\title{
Research on Serving the Development of Regional Economy Innovation by Intellectual Properties in Universities
}

\author{
Ge Li \\ Mathematics and Information Science school of Weinan Normal University, Weinan, China \\ Email: kiki74839@hotmail.com
}

Received November 2013

\begin{abstract}
At present, a sound intellectual property management and service system have not been established yet in Chinese colleges and universities. Meanwhile, the lost of existing intellectual property in universities due to small amount, low conversion rate, low technology content and weak brand awareness, hinders the positive effect of intellectual property and affects its transformation and application in China. This article introduces the current problems with intellectual property in universities and gives some countermeasures to promote the use of intellectual property in universities for a better regional economic service.
\end{abstract}

\section{Keywords}

Intellectual Property; Regional Economy; Enterprise; Universities

\section{Introduction}

With the country's increasing emphasis on education and the vigorous development of the universities, universities have become an important place for cultivating talents, developing science $\&$ technology and serving society. Serving regional economy also becomes an important function of universities. In China, as an important part of the national intellectual property system as well as an important base of knowledge and technological innovation, universities shoulder the important mission of creating intellectual property. However, due to our late start of university intellectual property strategy, obsolete concept, lack of incentives and other reasons, there are still many problems in using the intellectual property in universities for serving the local economy and creating social values compared with the developed countries. How to quickly transform universities' intellectual properties into productivity to promote economic development has become an important issue.

\section{Current Problems with Intellectual Property in Universities}

\subsection{Lack of Interaction Awareness}

In China, a reasonable and effective technology transfer platform between universities, enterprises and govern- 
ment has not been formed yet, and it severely limits the generation and promotion of the new technologies.

Currently, most of our universities' scientific and technological innovation are conducted around the research projects, the majority of which came from the research guide or tender subject issued by the higher authorities, or a deepen study on the declaring person's professional direction, the proportion of researches society-oriented or business-oriented in universities is relatively small. Many researches in universities are in a stage of "work behind closed doors". Universities often do not participate in the process of decision-making and consulting in local government departments or in the interaction with enterprises.

On the other hands, the enterprises pay more attention to the economic benefits of intellectual property, but concern little about the universities' research directions and research status, let alone understand and trust universities. The cooperation opportunity between them is quite little.

As the management departments of intellectual property, the government has many problems in the process of patent development, patent application, approval, and other services, such as patents publicity and social counseling is not sufficient; the service for intellectual property applicant and right holder is imperfect, which can not meet the needs of the society.

The lack of understanding and interaction between agencies has great impact on docking and coupling of the upstream, midstream and downstream in technological innovation, which is not conducive to the effective implementation of industry, academia, and research cooperation.

\subsection{Research Project Disconnect with the Practical Application}

Universities in China are still in the "supply-side" research mode. Based on national prescriptive technical research, the majority of achievements are away from the market, and difficult to meet the market demand. According to local authorities, the application value of achievements in universities is very low, the achievements transformed into market account for only about $8 \%$ of the total. The main reason is that there are many problems in universities' technology evaluation mechanism and incentive mechanism, and it directly hinders the transformation of scientific and technological achievements. For example, technology "Achievement Award" is the important criterion for promotion of institutional and technical positions in most universities, which directly result in the focus on scientific and technical research rather than their promotion; The assessment system are mostly concentrated in the longitudinal scientific and technical research, which affect the enthusiasm of the research staff to undertake horizontal researches, which account for merely about $20 \%$ of the total.

Because the performance evaluation system in universities is not perfect, The teachers and researchers in universities are generally concerned about the promotion, the paper, the workload and whether their project can be awarded, whether the research achievement can be generalized and promoted, and thus to generate social and economic benefits is not in their consideration. That is the reason why as an important scientific and technological research institution as universities, the market conversion rate of the scientific and technological research achievements are not high. Most of the achievements in universities just stay at the project level, and did not play a role in promoting the development of regional economy as well as society.

On the other hand, as a direct institution to transfer the scientific and technological achievements into productive forces, companies cannot carry out researches on all the issues having practical applications and demand due to limitations of scale, staff and funds, thus many meaningful studies have to be shelved .

\subsection{Personnel Training Divorced from Social Needs}

At present, universities in China generally lack of good managers who are independent of scientific and technological research management and good at operating intellectual property in the universities, so that the universities lack of effective management and control of intangible assets, such as patent and copyright. At present, the cultivation of intellectual property talent in our country gives particular attention to the legal talents, and lacks of plenty of technical talents and managerial talents for intellectual property [1]. Not well organized institutional settings for intellectual property and lack of professional makes it impossible to manage and protect the intellectual property effectively and throughout the whole process.

\subsection{Low Conversion Rate of Existing Intellectual Property}

Every year, nearly 10,000 of university research achievements pass the identification, of which more than $30 \%$ 
are in the international leading position or filled the domestic blank. Unfortunately, only $15 \%$ - $20 \%$ of these results are transferred into mass production; only $5 \%$ of the results are form the industrialization, and the patented implementation rate is only about $30 \%$. The vast majority of patents are shelved [2].

On the other hand, the research contents of universities and business needs are out of touch, problems such as the awareness of intellectual property in enterprise is not strong; the self-protection ability of intellectual property is low; the lack of intellectual property management departments in both universities and enterprises; the incentive and restraint mechanisms need to be strengthened; the intellectual property in enterprises has small amount and with low technological content and so on are greatly restrict Chinese intellectual property protection and the transformation of technological achievements.

As the project development in universities does not follow the market-oriented principles these days, a large number of scientific and technological achievements have no clear application object in the process of production and development, which nourishes a large number of patent having not market value or no real innovative content, and it directly leads to a large number of failure patent and low conversion patent rates. A survey showed that $25 \%$ of the companies believe that the research achievements provided by universities are poor maturity, low-matching performance, and unable to meet the business requirements of new technologies introduction [3].

\subsection{Short Protection Period for Intellectual Property}

The Chinese State Intellectual Property Office released report “Chinese valid patents Annual Report 2009” [4] in the March 2010 showed that the protection period of Chinese domestic effective invention patents were more concentrated in 3 to 6 years, while that of the foreign effective invention patents were focused on 5 to 8 years. That is to say, the protection period of both Chinese and foreign patents were not long, and that of Chinese patent is even shorter [5]. Compared with other innovation main part such as enterprises, the average lifetime of universities' patents is 2 to 3 years shorter [6]. The high early termination rate and the low maintenance rate of universities’ patents, especially the invention patents, can not satisfy the socio-economic development [7].

\subsection{Not Enough Importance Attached to PCT}

As an important indicator to measure the national technological position, PCT (Patent Cooperation Treaty) applications directly signify the country's strength in the particular technical field [8]. Taking Shaanxi Province as an example, it has a total of 43,608 patent applications in the year of 2012, where the university patent applications are 8247, only accounting for 18.9 percent of the total. Yet the number of international patent application PCT is only 125. It is easy to tell from these figures that the majority of university patents focus mainly on Chinese patents, while ignore the international patent applications, which makes many patents lost a wider range of protection and the economic value they deserve. According to some reports, between the year 1985 and 1999 , 113,000 patents in China applied only for domestic patent dedicated to the world free of charge.

\section{Countermeasures to Promote the Use of Intellectual Property in Universities for a Better Regional Economic Service}

Use of innovative intellectual property in universities to serve regional economic development is not only an important task for the self-development of colleges and universities, but also the urgent need for regional economic and social development. How to strengthen the interaction between universities and enterprises in the region, and to establish a long-term cooperation mechanism through government regulation, is now an important question for government, enterprises and universities.

\subsection{Promoting Interaction between Universities and Enterprises, and Establishing a Long-Term Cooperation Mechanism}

It is pointed out in "Long-term Educational Reform and Development Plan (2010-2020)" that: "We should establish a school system that led by government, guided by industry and have the participation of enterprises, formulate school regulations that promoting school-enterprise cooperation, and promote the institutionalization of school-enterprise cooperation. Preferential policies should be formulated to encourage enterprises to receive 
practical training of students and teachers, to encourage enterprises to increase the investment in vocational education.”

As a professional management institution for intellectual property, the local Intellectual Property Office should provide more communication channels and bridges for universities who create intellectual property and for enterprises that use intellectual property, provide a platform for mutual understanding and communication between universities and local enterprises, and promote the cooperation between them.

Government should give full play to its guiding function and regulation function to develop an economyoriented technological innovation strategy and technological innovation incentives policy in line with the market for the universities. It should also support and make preferential policies for the market-oriented research, thus to accelerate the generation and the transformation of intellectual property. Meanwhile it should provide wider opportunities for enterprises in the form of financial support, project support, government guarantees, and etc. Various social resources including government, enterprises and universities can be integrated to build a platform for cooperation of Industry, Education and Academy and also to promote the establishment of long-term cooperation mechanism between universities and enterprises, thus to improve the university's research capacity, to enhance the core competitiveness of related industries, and to promote the development of regional economic.

Except the completion of research tasks assigned by the parent unit, universities should also commit to the research that the local government needed and solve specific problems together with the government, and actively participate in the development of regional policy advisory work.

\subsection{Establishing Intellectual Property Strategic Alliances}

The globalization of economic development makes the rapid respond to innovation becomes the key to victory in enterprise competition. However, the high cost and high risk of innovation make a lot of enterprises can not create innovation activities independently, regional enterprises can work together with universities to overcome technical problems, develop new products \& processes through university science park, technology research and development centers, cooperation projects and other ways. It enhances the core competitiveness of enterprises and improves the innovation capabilities of universities and meanwhile accelerates the production, transformation and application of intellectual property.

Through the establishment of Intellectual Property Alliance, regularly meetings, distribution of new trends in the industry, establishment of a shared information platform and other ways, the cooperation and exchanges between universities and companies can be promoted, and the impact of intellectual property in universities and enterprises can be enlarged. Also it provides more opportunities for market applications of intellectual property, so as to promote better the development of regional economy.

\subsection{Improve Intellectual Property Management Mechanisms}

Currently, the majority of our colleges and universities have not specialized intellectual property management department, and the management of intellectual property in many colleges and universities are in the Science and Technology Department. Neither do they have a sound intellectual property management and incentive mechanisms for university's intellectual property, so that many teachers and researchers in universities are unclear on the concept of intellectual property, not to mention the creation and application of intellectual property.

In early 2000s, Japan made “Intellectual Property nation” slogan, and mobilizing industry, government and academia to actively promote policies [9], which has achieved remarkable results. We can fully learn the best practices of the developed countries to promote the standardized and scientific management of intellectual property in universities by establishing dedicated intellectual property management department, reforming the research incentive mechanism and developing sound policies and regulations system [10].

\subsection{Cultivating Intellectual Professionals}

Combined with the regional economic and personnel needs, the university may change the original professional setting or add specialized courses or elective courses, to cultivate a number of compound talents both having lifelong learning ability based on profession and proficient in laws \& regulations, declaration and application of intellectual property. And also by way of establishing intellectual property training base, universities can hold regularly or irregularly intellectual property training or internships for university researchers, students, em- 
ployees and government officials. By these means the awareness and influence of intellectual property in public are enlarged, and thus the universities' ability of serving regional economy and social development can be enhanced.

\subsection{Make Full Use of Science and Technology Agency}

The science and technology agency can provide scientific guidance and evaluation for the universities' patent transformation. Before the patent application, universities can ask the science and technology agency for a preliminary assessment of commercial value of the patent, to ensure that only technology having the prospect of industrialization will be considered the patent application, and to curb the generation of foam patent from the source [11]. Meanwhile, the truly high-quality patent with market competitiveness can be better supported and protected by such assessment.

\section{Conclusion}

Compared to developed countries, the transformation and application of intellectual property in universities have made some achievements, but there are still many problems. Facing fierce market competition and the urgent need for knowledge innovation, it is necessary for universities, enterprises and government to develop strategies to improve the universities' innovation capacity and to accelerate the industrialization of core patented technology to provide strong support for sustained and coordinated economic and social development.

\section{Funding}

This project is sponsored by ZL2014-13, 13SKYB013, 13JZ004.

\section{References}

[1] Xingke, H. (2010) Comparative Analysis of Chinese Universities Patent Output Condition. Tianjin University, Tianjin.

[2] GonG, J.P., Li, C. and Tang, F. (2011) Intellectual Property Management in University Technology Transfer. Research and Development Management.

[3] Xu, N. and Ma, Y.Q. (2013) Scientific Achievement Transformation Path Dependence. Social Scientists.

[4] Yu, D.W. and Wang, X.H. (2011) 2009Annual Report of China Valid Patent. Science Focus, 2, 33-50.

[5] Qiao, Y.Z. (2011) Factors Influencing Patent Maintenance Time. Science Research Management, 32, $143-149$.

[6] Yang, F. and Fu, J. (2006) Valuation and Legal Problems of Valuation Patent Technology Transfer in Universities. Technology Progress and Policy, 6, 131-133

[7] Wang, N. (2009) Research on Situation, Problems and Countermeasures in University Patent. Technology Management Research, 3, 145-147.

[8] Mansfield, E. (1984) R\&D and Innovation: Some Empirical Findings. In: Zvi, G., Ed., R\&D, Patents and Productivity, University of Chicago Press for the National Bureau of Economic Research, Chicago.

[9] Zheng, Y.J. and Sun, J. (2007) The Basic Idea of Intellectual Property Complex Talent Training Plan. Electronic Intellectual Property, 1, 40-44.

[10] European Commission Working Paper (1984) Strategic Dimensions of Intellectual Property Rights in the Context of S \& T Policy, 33.

[11] Lanjouw, O.L., Pakes, A. and Putnam, J. (1998) How to Count Patents and Value Intellectual Property: Uses of Patent Renewal and Application Data. The Journal of Industrial Economics, 46, 405-432. http://dx.doi.org/10.1111/1467-6451.00081 